\title{
A Pedagogia da Alternância no contexto da Educação do Campo: a experiência do Instituto Educar
}

\author{
Luana Bonavigo $^{1}$, Flávia Eloisa Caimi ${ }^{2}$ \\ ${ }^{1}$ Centro de Ensino Superior Riograndense/Instituto Educar. Programa de Pós-Graduação em Educação. Rua \\ Duque de Caxias, 990. Ronda Alta - RS. Brasil. luanabbonavigo@gmail.com. ${ }^{2}$ Universidade de Passo Fundo - \\ $\mathrm{UPF}$
}

\begin{abstract}
RESUMO. Superando-se a visão urbanocêntrica, em que o campo é tido como lugar de atraso, e ultrapassando-se a perspectiva de antagonismo entre cidade-campo, busca-se reconhecer tempos e modos específicos de ser, viver e produzir, concebendo a educação e a escola segundo diferentes formatos de organização, de acordo com as necessidades das populações que vivem do/no campo. Com base nesses pressupostos, a educação do/no campo circunscreve a temática geral deste artigo, onde se busca travar diálogo com a Pedagogia da Alternância como alternativa para viabilizar uma proposta educativa que possa fazer frente às demandas e especificidades dessas populações. Trata-se de um estudo de caráter bibliográfico, que se volta para o entendimento contextual, histórico e conceitual da Educação do Campo e da Pedagogia da Alternância, combinado à investigação exploratória das práticas educativas pautadas na experiência da alternância, que se realizam no Instituto Educar de Pontão/RS. Conclui-se que o Instituto Educar assume uma organização metodológica alternante entre Tempo Escola e Tempo Comunidade, prioriza a educação dos sujeitos inseridos em uma coletividade e confere protagonismo aos educandos que ali desenvolvem seus processos formativos.
\end{abstract}

Palavras-chave: Educação do Campo, Pedagogia da Alternância, Tempo Escola, Tempo Comunidade. 


\title{
The Pedagogy of Alternation in the Context of Rural Education: the experience of the Educar Institute
}

\begin{abstract}
Overcoming the urban-centric vision, where the countryside is considered a place of backwardness and surpassing the perspective of city-countryside antagonism, this paper intend to recognize specific times and ways of being, living and producing, conceiving education and school by different organizational formats, according to the needs of the population living in/from the countryside. Based on this assumption, education in the countryside circumscribes the general theme of this article, aiming to establish a dialogue with the Alternation Pedagogy as an alternative to enable an educational proposal that can meet the demands and specificities of these populations. This is a bibliographical study focused on the contextual, historical and conceptual understanding of rural education and the Alternation Pedagogy, combined with the exploratory investigation of educational practices based on alternation experiences carried out at the "Instituto Educar" in Pontão/RS. The conclusion is that Instituto Educar assumes an alternating methodological organization between School Time and Community Time, prioritizes the education of the subjects inserted in a collectivity and confers protagonism to the students who develop their formative processes there.
\end{abstract}

Keywords: Rural Education, Alternation Pedagogy, School Time, Community Time. 


\section{La Pedagogía de la Alternancia en el contexto de la Educación del Campo: la experiencia del Instituto Educar}

RESUMEN. Superando la visión urbanocéntrica, en que el campo es considerado como lugar de retraso, y superando la perspectiva de antagonismo entre ciudad-campo, se busca reconocer tiempos y modos específicos de ser, vivir y producir, concibiendo la educación y la escuela según diferentes formatos de organización, de acuerdo con las necesidades de las poblaciones que viven del/en el campo. Con base en este presupuesto, la educación del campo circunscribe la temática general de este artículo, donde se busca frenar diálogo con la Pedagogía de la Alternancia como alternativa para viabilizar una propuesta educativa que pueda hacer frente a las demandas y especificidades de esas poblaciones. Se trata de un estudio de carácter bibliográfico, que se vuelve hacia el entendimiento contextual, histórico y conceptual de la Educación del Campo y de la Pedagogía de la Alternancia, combinado a la investigación exploratoria de las prácticas educativas pautadas en la experiencia de la alternancia, que se realizan en el Instituto Educar de Pontão/RS. Se concluye que el Instituto Educar asume una organización metodológica alternante entre Tiempo Escuela y Tiempo Comunidad, prioriza la educación de los sujetos insertados en una colectividad y confiere protagonismo a los educandos que allí desarrollan sus procesos formativos.

Palabras clave: Educación del Campo, Pedagogía de la Alternancia, Tiempo Escuela, Tiempo Comunidad. 


\section{Introdução}

O Instituto Educar é uma escola do e no campo que nasceu da força do Movimento dos Trabalhadores Rurais Sem Terra (MST), num contexto de lutas em prol de uma educação voltada a seus povos, cuja proposta pedagógica enseja uma organização na qual o educando alterna entre períodos de internato em tempo integral na escola e períodos de permanência na família/comunidade. Essa alternância tem como objetivo manter os alunos próximos do seu local de residência, vivenciando seus aprendizados na teoria e na prática, constituindo-se como uma possibilidade singular de Educação do e no Campo.

No intuito de cultivar processos formativos humanos, a Educação do Campo se constrói gradativamente e simboliza um feito recente de conquistas idealizadas pelos trabalhadores rurais $\mathrm{e}$ suas organizações. $\mathrm{O}$ movimento que busca uma Educação do e no Campo vem se consolidando na sociedade brasileira por lutas sociais que há muito tempo denunciam os processos de exclusão enfrentados pelos sujeitos que vivem em tais contextos. Essa exclusão se caracteriza diante de seus direitos à terra, à educação, à moradia, à cultura e à vida.

De acordo com Caldart (2002), a Educação do Campo, vista a partir da sua constituição histórica, se efetivou mediante lutas sociais que buscavam os direitos da população do campo. Assim, foi se construindo por meio da pressão social de povos que se preocupavam com a consolidação de políticas públicas de caráter coletivo que visassem à estruturação de uma educação dos camponeses e não apenas para os camponeses.

Situamos nosso estudo sobre o pressuposto de que a Educação do Campo, em permanente construção, visa ao reconhecimento das necessidades, das capacidades e dos interesses da população que vive, trabalha e sobrevive do e no campo. Desse modo, evidencia-se a necessidade de pensar alternativas educativas que correspondam às suas demandas. Uma das práticas educativas que se destaca nos estudos sobre Educação do Campo é a Alternância, caracterizandose como uma organização que permite a vivência dos sujeitos intercalando tempos formativos entre a escola e a comunidade, podendo ser utilizada como uma pedagogia em si ou como uma forma de organização metodológica.

Assim, neste artigo tem-se o objetivo de analisar o contexto abrangente, histórico e social da Educação do Campo e compreender as possibilidades da Alternância como prática educativa, para então investigar as especificidades do 
Instituto Educar. Para tal, abordamos inicialmente o contexto mais amplo da Educação do Campo e da Pedagogia da Alternância para, posteriormente, chegar aos fundamentos específicos do Instituto Educar, realizando uma inserção exploratória com vistas a analisar a construção cultural e histórica implicada no desenvolvimento dos processos educativos.

\section{Da Educação Rural à Educação do Campo: um histórico de lutas}

Segundo Caldart (2002), a Educação

do Campo deve ser compreendida mediante um olhar voltado às construções elaboradas ao longo dos anos por movimentos que lutam pela garantia dos direitos da população do campo. Como traço marcante, é possível identificar a luta constante para que o ensino seja entendido em dupla acepção, no e do campo: "No: o povo tem direito de ser educado no lugar onde vive. Do: o povo tem direito a uma educação pensada desde seu lugar e com a sua participação, vinculada à cultura e às suas necessidades humanas e sociais" (Caldart, 2002, p. 18).

Segundo informações documentadas pela Secretaria de Educação Continuada, Alfabetização, Diversidade e Inclusão (Secadi), no caderno temático sobre a Educação do Campo publicado pelo Ministério da Educação (Brasil, 2007), desde a colonização do Brasil os trabalhadores rurais foram explorados e impedidos de acessar as mesmas condições que os conterrâneos do meio urbano, o que gerou

um forte preconceito em relação aos povos que vivem e trabalham no campo, bem como uma enorme dívida social. Ao mesmo tempo, a suposição de que o conhecimento "universal", produzido pelo mundo dito civilizado deveria ser estendido ou imposto - a todos, de acordo com a "capacidade" de cada um, serviu para escamotear o direito a uma educação contextualizada, promotora do acesso à cidadania e aos bens econômicos e sociais, que respeitasse os modos de viver, pensar e produzir dos diferentes povos do campo. Ao invés disso, se ofereceu, a uma pequena parcela da população rural, uma educação instrumental, reduzida ao atendimento de necessidades educacionais elementares e ao treinamento de mão de obra (Brasil, 2007, p. 10).

O referido caderno temático revela que durante anos a preocupação educacional do país priorizou a elite brasileira que, frente ao crescimento das favelas na periferia urbana, percebia a educação rural como meio de conter o fluxo de migração do campo para a cidade. Em 1961, a Lei de Diretrizes e Bases da Educação Nacional (Lei $\mathrm{n}^{\circ}$. 4.024/61) afirma esse caráter instrumentalista e de ordenamento social, adotando a Educação Rural como forma de favorecer a adaptação do sujeito ao seu meio para, 
assim, manter a população do campo na zona rural (Brasil, 2007).

Buscando a participação das camadas populares, houve a mobilização de educadores, religiosos e de alguns partidos políticos para a organização de um movimento de educação popular que reivindicava a construção de uma educação voltada às necessidades e particularidades culturais dos povos do campo. No contexto de luta pelo fim da ditadura civil-militar, as organizações ligadas à educação popular, já na década de 1980, incluíam a Educação do Campo como tema estratégico para a redemocratização do país. As organizações sociais aliam-se a organizações comunitárias do campo, a sindicatos de trabalhadores rurais, a partidos políticos de esquerda e a educadores resistentes à ditadura militar.

Ganham destaque, na luta por um sistema público de ensino para o campo, as ações educativas do Movimento dos Trabalhadores Rurais Sem Terra (MST), da Comissão Pastoral da Terra (CPT), do Movimento de Educação de Base (MEB) e da Confederação Nacional dos Trabalhadores na Agricultura (Contag). Ao mesmo tempo, para agregar força às mobilizações, emergem, inspiradas em modelos franceses, as Escolas Famílias Agrícolas (EFA) e as Casas Familiares Rurais (CFR), instituições que preconizavam uma proposta pedagógica para a educação no meio rural a partir da Pedagogia da Alternância, que possibilitasse aos educandos a divisão sistemática do tempo de formação entre o campo e a escola (Brasil, 2007).

No ano de 1988 é promulgada a nova Constituição da República Federativa do Brasil, que reafirma o Estado Democrático e assegura o compromisso da União em promover a educação para todos, com respeito às diferenças culturais e regionais. Em dezembro de 1996 se estabelece a nova Lei de Diretrizes e Bases da Educação Nacional (Lei $\mathrm{n}^{\circ}$. 9.394/96), que propõe diretrizes e bases comuns de ensino para todas as regiões, adequando a educação às diferenças regionais e rurais (Brasil, 1996). Essa Lei é considerada um marco que insere a Educação do Campo na política educacional.

As lutas pela democratização do ensino no meio rural são fortemente protagonizadas pelos militantes da reforma agrária. O conceito inicialmente foi explorado como Educação Básica do Campo em discussões nacionais que partiram das mobilizações realizadas pelo MST. Com o pressuposto de construção de uma escola voltada para a realidade dos trabalhadores rurais, o referido Movimento vem, há décadas, lutando por políticas públicas em instâncias locais, estaduais e nacionais que correspondam às suas necessidades. 
Um marco histórico representativo dessa luta pela educação situa-se no ano de 1997, quando o MST em parceria com a Universidade de Brasília (UnB), com o Fundo das Nações Unidas para a Infância (Unicef), com a Organização das Nações Unidas para a Educação, a Ciência e a Cultura (Unesco) e com a Conferência Nacional dos Bispos do Brasil (CNBB), organizou o primeiro Encontro Nacional de Educadoras e Educadores da Reforma Agrária (Enera). Nesse encontro, os debates visavam às experiências educativas do MST, assim, as discussões pautaram-se pela construção de uma proposta que atendesse às especificidades dos sujeitos do campo, ficando explícita, pela perspectiva dos participantes, a insuficiência da oferta educacional para esses povos (Santos, Molina \& Jesus, 2010).

O primeiro Enera consolidou um grupo representativo para tomar frente no processo de construção de um projeto educacional que considerasse a perspectiva dos trabalhadores do campo. Herdeiro desse encontro é criado no ano de 1998 o Programa Nacional de Educação na Reforma Agrária (Pronera), que se constituiu como uma política pública de Educação do Campo, instituída no âmbito do Ministério do Desenvolvimento Agrário (MDA) e executada a partir do ano de 2001 pelo Instituto Nacional de
Colonização e Reforma Agrária (Incra) (Santos, Molina \& Jesus, 2010).

No ano de 2001 é aprovado pelo Conselho Nacional de Educação (CNE) o Parecer $n^{\circ} 36 / 2001$ que, ao se referir à Lei de Diretrizes e Bases da Educação Nacional (Lei 9.394/96), propõe medidas de adequação dos sistemas da escola à vida no campo. As condições apresentadas nesse parecer revelam as percepções históricas que circundam a utilização do termo Educação Rural, deixando explícita a concepção de Educação do Campo que, mesmo

tratada como educação rural na legislação brasileira, tem um significado que incorpora os espaços da floresta, da pecuária, das minas e da agricultura, mas os ultrapassa ao acolher em si os espaços pesqueiros, caiçaras, ribeirinhos e extrativistas. $\mathrm{O}$ campo, nesse sentido, mais do que um perímetro não-urbano, é um campo de possibilidades que dinamizam a ligação dos seres humanos com a própria produção das condições da existência social e com as realizações da sociedade humana (Brasil, 2001, p. 01).

Esse parecer provocou a incorporação de argumentos que contemplam a mudança do termo Educação Básica do Campo para Educação do Campo, visto que o direito à educação abrange desde a educação infantil até o ensino superior (Caldart, 2013). No ano de 2003, o Ministério da Educação criou, através da Portaria n 137 de 03 de junho, o 
Grupo Permanente de Trabalho (GPT) de Educação do Campo. O GPT, no ano de 2004, publicou um caderno intitulado Referências para uma Política Nacional de Educação do Campo, com o objetivo de expandir as discussões no âmbito político e social "com vistas à formulação e implementação de políticas de educação e de desenvolvimento sustentável do campo" (Brasil, 2004, p. 5).

Em 2004 também é criada, no âmbito do Ministério da Educação, a Secadi ${ }^{\mathrm{i}}$, vinculando uma coordenação de Educação do Campo. No mesmo ano destaca-se, ainda, a realização da II Conferência Nacional por uma Educação do Campo, com o lema "Educação do Campo: direito nosso, dever do Estado!” Caldart (2013) ressalta que o encontro contou com um número expressivo de participantes das mais diversas instituições e proporcionou momentos de explanação de projetos e a organização de entidades para integrar a Articulação Nacional por uma Educação do Campo.

No ano de 2007, a Secadi/MEC publicou um caderno temático que descreve a trajetória da Educação do Campo destacando, naquele momento, a primazia pela inclusão social e pela diversidade. Os escritos enfatizam que o ensino para a população camponesa deveria abranger as diferenças culturais e sociais e não apenas geográficas, um pensamento que reflete um histórico de lutas sociais pelos direitos da população campesina (Brasil, 2007).

Em 2010 é criado o Fórum Nacional de Educação do Campo (Fonec), com o objetivo de exercer

$$
\begin{aligned}
& \text { análise crítica constante, severa e } \\
& \text { independente acerca de políticas } \\
& \text { públicas de Educação do Campo; } \\
& \text { bem como a correspondente ação } \\
& \text { política com vistas à implantação, à } \\
& \text { consolidação e, mesmo, à elaboração } \\
& \text { de proposições de políticas públicas } \\
& \text { de Educação do Campo (Fonec, } \\
& \text { 2010, p. 1). }
\end{aligned}
$$

No mesmo ano é estabelecido o Decreto $\mathrm{n}^{\mathrm{o}} 7.352 / 2010$, que dispõe sobre a política de Educação do Campo e o Pronera. Efetiva-se, nesse momento, o comprometimento da União, em colaboração com os estados e municípios, com o desenvolvimento de um regime de ampliação e qualificação da educação básica e superior às populações do campo de acordo com o Plano Nacional de Educação (PNE 2001-2010) (Brasil, 2010).

O Pronera tem o objetivo de fortalecer a educação na reforma agrária, desenvolvendo projetos educacionais com metodologias voltadas à população do campo, tendo como princípios a promoção do desenvolvimento e a ampliação das condições democráticas a esses cidadãos (Santos, Molina \& Jesus, 2010). O público alvo dos programas é composto por jovens e adultos dos projetos de assentamentos 
criados pelo Incra. Conforme dados disponibilizados por essa instituição ${ }^{\mathrm{ii}}$, até maio de 2016 o Pronera contava com 167.648 mil alunos atendidos pela Educação de Jovens e Adultos (EJA), 9.116 alunos já formados em nível médio, 5.347 alunos graduados em nível superior, 1.765 alunos especialistas em nível de pósgraduação e 1.527 alunos em Residência Agrária Nacional (Incra, 2016).

A atuação do Pronera se efetiva por meio de parcerias das instituições públicas de ensino, das instituições comunitárias sem fins lucrativos e dos governos estaduais e municipais com os movimentos sociais e sindicais de trabalhadores e trabalhadoras rurais. Em decorrência de uma dessas parcerias, no ano de 2005 se consolida a criação do Instituto Educar, uma escola do campo fruto da conquista dos Trabalhadores Rurais Sem Terra, durante uma caminhada de luta pela reforma agrária, priorizando as mudanças estruturais na organização e nas relações sociais no campo.

De acordo com Caldart (2002), a Educação do Campo prioriza a diversidade humana em suas dimensões histórica, política e social, concebendo o sujeito como protagonista de sua formação. A escola, nessa perspectiva, é objeto central de constantes reflexões, tendo os educadores papel fundamental na formulação pedagógica. Conforme o
Decreto $\mathrm{n}^{\mathrm{o}} 7.352 / 10$, são princípios da Educação do Campo:

I - respeito à diversidade do campo em seus aspectos sociais, culturais, ambientais, políticos, econômicos, de gênero, geracional e de raça e etnia; II - incentivo à formulação de projetos político-pedagógicos específicos para as escolas do campo, estimulando o desenvolvimento das unidades escolares como espaços públicos de investigação e articulação de experiências e estudos direcionados para o desenvolvimento social, economicamente justo e ambientalmente sustentável, em articulação com o mundo do trabalho;

III - desenvolvimento de políticas de formação de profissionais da educação para $\mathrm{o}$ atendimento da especificidade das escolas do campo, considerando-se as condições concretas da produção e reprodução social da vida no campo;

IV - valorização da identidade da escola do campo por meio de projetos pedagógicos com conteúdos curriculares e metodologias adequadas às reais necessidades dos alunos do campo, bem como flexibilidade na organização escolar, incluindo adequação do calendário escolar às fases do ciclo agrícola e às condições climáticas;

$\mathrm{V}$ - controle social da qualidade da educação escolar, mediante a efetiva participação da comunidade e dos movimentos sociais do campo (Brasil, 2010, s/p).

Uma educação que se compromete com a população do campo empenha-se em fomentar discussões sobre aspectos trabalhistas e aspectos educacionais, cujo entendimento não se restringe ao entorno de uma qualificação para o mercado de trabalho, mas sim, da preparação ampla 
para a vida. O compromisso é pensar o trabalho como locus de formação humana, tendo em vista o educando em interação com as relações sociais, culturais e políticas. Trata-se de construir um processo de formação que não esteja em consonância apenas com os interesses capitalistas, mas que seja próximo da realidade das camadas populares trabalhadoras do campo (Menezes \& Neto, 2009).

A questão pedagógica que se coloca para a Educação do Campo tenciona a recuperação do vínculo entre formação humana e produção material da existência (Caldart, 2013). Nesse sentido, a intencionalidade educativa enfatiza padrões de relações sociais que não excluem os povos do campo, mas que lhes garante o direito de pensar a pedagogia partindo das particularidades de seu contexto. Caldart (2013) salienta que pensar os vínculos diante de uma realidade específica é uma contribuição original da Educação do Campo, é analisar a relação “com a produção na especificidade da agricultura camponesa, da agroecologia; o trabalho coletivo... Vida humana misturada com terra... Ciência, tecnologia, cultura, arte potencializadas como ferramentas de superação da alienação" (Caldart, 2013, p. 262).

Para a efetivação dos princípios pedagógicos da Educação do Campo, algumas experiências vêm sendo efetivadas e se constroem percorrendo a mesma caminhada de luta por uma educação que considere as particularidades da população camponesa. Destacam-se, nesse sentido, as seguintes organizações: as escolas localizadas em assentamentos da reforma agrária, que se pautam nos estudos do MST, as CFR e as EFA, que seguem os princípios europeus da Pedagogia da Alternância.

\section{A Pedagogia da Alternância como uma modalidade à Educação do Campo}

As primeiras discussões da Alternância como prática educativa no mundo emergiram no ano de 1935, na região Sudeste da França (Estevam, 2001; Begnami, 2003; Gimonet, 2007; Sobreira \& Silva, 2014). Nos anos de 1930 a Europa transitava por um contexto trágico, entre as duas guerras mundiais, e a França, nesse cenário, buscava sua reconstrução diante das grandes perdas que levaram à destruição social e econômica do país. Um dos setores da economia francesa mais afetados foi a agricultura que, em decorrência disso, sofreu com o desinteresse do Estado, vivendo um período de grandes dificuldades. Além desses problemas, o sistema de educação na França estava direcionado aos contextos urbanos e o ensino para a população rural se tornava inacessível. Os indivíduos que 
desejavam estudar precisavam abandonar suas casas e, tendo em vista que a sobrevivência das famílias dependia da agricultura, mudar-se para a cidade significava a perda de uma mão de obra fundamental (Estevam, 2001).

Begnami (2003) refere que na França pós Primeira Guerra Mundial enfrentava-se um grave êxodo rural, os jovens que escolhiam ficar no campo não possuíam formação adequada e aqueles que optavam por estudar deixavam suas propriedades para morar nas cidades. O sistema educacional da França não estava acolhendo as necessidades do meio rural, razão pela qual moradores rurais franceses, insatisfeitos com essa situação, se uniram e iniciaram um movimento em busca de uma educação que considerasse os ideais do campo.

$\mathrm{O}$ agricultor Jean Peyrat foi um dos pioneiros na luta camponesa na França que, depois de se decepcionar ao ver seu filho Ives abandonar os estudos ao não se adaptar à escola urbana optando apenas pelo trabalho no campo, procura o Padre Granereau, amigo de movimento social, para expor suas angústias diante da situação dos povos rurais. Ambos, o agricultor e o padre, passam a reunir os povos rurais difundindo uma idealização de escola alternativa do campo. Os pioneiros rapidamente ganharam a adesão do povo, que se juntou na luta por uma formação integral, humanista e profissional direcionada ao campo (Begnami, 2003).

O grupo de agricultores franceses buscava uma educação organizada, que atendesse às especificidades dos jovens, com vistas a uma formação que dialogasse com os preceitos agrícolas fundamentais para o desenvolvimento de sua região. Iniciaram com uma experiência organizada pelo Padre Granereau, que cedeu um espaço da própria paróquia para as aulas e assumiu a responsabilidade de ser o primeiro monitor. A experiência foi alcançando resultados significativos, de modo que alunos, famílias e comunidade assumiram juntos a tarefa de fortalecer esse processo. No ano de 1937 essa experiência se oficializou e as famílias criaram uma associação. Em 1941 adotaram um estatuto independente $\mathrm{e}$ institucionalizaram a primeira Associação Maison Familiale de Lauzun (Casa Familiar de Lauzun). Os resultados positivos começaram a ganhar força e a se multiplicar em âmbito nacional, passando a se denominar Maison Familiale Rurale (Casa Familiar Rural) os lugares dedicados ao ensino desses povos (Begnami, 2003).

Diante da necessidade de formação dos jovens agricultores, as Maisons francesas buscavam ações educativas que preparassem para uma formação geral e técnica, cujo objetivo maior girava em torno da transformação de sua realidade na 
busca constante de interação entre ação e reflexão. Decorre, a partir desse momento histórico, um longo processo de progressos e retrocessos, uma caminhada de superação que nunca se findou, mas que, baseada em atender às necessidades do povo rural, se reconstruiu conforme as exigências da sociedade.

É importante ressaltarmos que a construção pedagógica da Alternância não se baseou em métodos ou teorias já concretizadas, mas, sobretudo pautou-se nos interesses dos agricultores e foi se constituindo conforme os resultados das primeiras experiências. Assim, foi um processo mediante o qual os alunos, famílias e comunidades foram porta-vozes que

perceberam, escutaram e se conscientizaram dos problemas, das necessidades. Questionaram-se, formularam hipóteses e têm enunciado soluções ... inventaram, realizaram, agiram, implementaram, arriscaram. Uma vez engajada na ação, observaram, escutaram, olharam as práticas. Analisaram, destacaram os componentes do sistema e os fatores de êxito e de fracasso ... extraíram ideias, pensamentos, saberes e conhecimentos ... para entender melhor, agir melhor a fim de prestar um serviço educativo, responder às necessidades, contribuir para $\mathrm{o}$ desenvolvimento das pessoas e do meio rural (Gimonet, 2007, p. 27).

Dessa forma, a experiência pedagógica alternante foi aos poucos logrando êxitos e se multiplicando pelo mundo. No caso do Brasil, a Pedagogia da Alternância surgiu no ano de 1969, no Espírito Santo e, após essa data, percorreu um longo caminho até ser reconhecida e efetivada em diversas experiências educativas do campo. Esse primeiro movimento foi influenciado por um padre vindo da Itália para atuar em uma região ocupada por descendentes italianos, ao perceber que essa região poderia se adaptar a um projeto italiano de seu conhecimento denominado EFA. Em discussão com a comunidade, inauguraram no ano de 1968 a primeira EFA do Brasil, no mesmo ano em que foi criado o Movimento de Educação Promocional do Espírito Santo (Mepes), para representar os agricultores com ações na área da educação, saúde e ação comunitária. As primeiras experiências educacionais iniciaram, como já dito, no ano de 1969 e se expandiram para outros estados, o que possibilitou a criação da União Nacional das Escolas Famílias Agrícolas do Brasil (Unefab), que passou a coordenar as atividades, defendendo os interesses dos agricultores (Estevam, 2001).

O sistema adotado pelas EFA brasileiras manteve o regime de alternância, caracterizado por uma semana na escola e uma semana na propriedade, para os estudantes do ensino fundamental; e de 15 dias na escola e 15 dias na 
propriedade, para os estudantes do ensino médio. O principal objetivo das EFA era de atuar sobre os interesses do homem do campo e, visto que no momento de sua consolidação o estado do Espírito Santo passava por uma crise econômica e social, buscar uma elevação cultural, social e econômica do seu povo (Estevam, 2001).

Nos anos de 1980 surge no Brasil uma segunda experiência, desvinculada das EFA, que visava à implementação das CFR na região Nordeste. Esse movimento contou com influência direta das Maisons francesas que se voltaram primeiramente a essa região devido ao momento educacional que estava vivenciando com o desenvolvimento de programas realizados pela Superintendência do Desenvolvimento do Nordeste (Sudene). No Sul do Brasil, o processo de implantação das CFR iniciou no Paraná no ano de 1987 e contou com um expressivo apoio do governo paranaense. A institucionalização do projeto permitiu sua rápida expansão aos outros estados do Sul e culminou na criação da Associação Regional das Casas Familiares Rurais do Sul do Brasil (Arcafar-Sul), que passou a coordenar os projetos das CFR (Estevam, 2001).

No Rio Grande do Sul, a primeira experiência que adotou a Pedagogia da Alternância como proposta metodológica ocorreu no norte do estado, mediante a criação da Casa Familiar Rural Santo
Isidoro (CFRSI), que começou suas atividades no ano de 2002 no município de Frederico Westphalen. A CFRSI se constituiu ligada à Associação Regional das Casas Familiares Rurais do Rio Grande do Sul (Arcafar-RS) que é filiada à Arcafar-Sul. Já, no ano de 2009 foi criada, no município de Santa Cruz do Sul, a primeira EFA no Sul do Brasil, denominada Escola Família Agrícola de Santa Cruz do Sul (Efasc). Essa se constituiu ligada à Associação Gaúcha PróEscolas Famílias Agrícolas (Agefa) que é filiada à União Nacional das Escolas Famílias Agrícolas do Brasil (Unefab) e à Associação Internacional dos Movimentos Familiares de Formação Rural (AIMFR).

Aos poucos, as experiências em alternância foram sendo divulgadas por todo o país e ganharam ampla adesão dos movimentos sociais que lutavam pelo direito dos pequenos agricultores, tendo o MST como um forte precursor na luta pela educação campesina. No processo de sua construção pedagógica constituíram a chamada Pedagogia do Movimento, que tem como um de seus pilares de sustentação a Alternância. Inspirado nas experiências produzidas em escolas do campo, o MST incorpora como preceito fundamental a integração entre escola, família, sujeito e comunidade (Kolling, Vargas \& Caldart, 2013). 
A Lei 9.394/96, ao estabelecer as Diretrizes e Bases da Educação Nacional aborda, no Artigo 23, a possibilidade de a educação básica se organizar em "séries anuais, períodos semestrais, ciclos, alternância regular de períodos de estudos, grupos não-seriados, com base na idade, na competência e em outros critérios, ou por forma diversa de organização" (Brasil, 1996, s/p). Mediante respaldo legal, diversas experiências vêm sendo vivenciadas no Brasil com base na Pedagogia da Alternância. Nelas, busca-se manter os objetivos fundantes da Alternância, que visam articular atividades escolares e práticas, tendo em vista a proximidade do aluno com o seu contexto. No momento, pesquisadores e entidades sugerem a utilização da terminologia Centros Familiares de Formação por Alternância (CEFFA) ao se referirem às instituições do campo que assumem a Alternância como práxis pedagógica (Teixeira, Bernartt \& Trindade, 2008).

Expomos, a seguir, a caracterização da Alternância como prática pedagógica, assim como seus pressupostos, organização metodológica, finalidades, métodos e instrumentos educativos. De imediato, compreende-se que a proposta pedagógica da Alternância se elabora a partir do pressuposto ideológico de que a experiência vivida é fundamental na formação dos jovens (Gimonet, 2007). Sua metodologia se organiza de modo que o educando passe um período de contato direto com a escola e outro período de contato direto com sua comunidade. Todas as atividades são articuladas através de um Projeto Político-Pedagógico (PPP), que vincula "comunidade e escola, projetos e currículo, realidade social e escola" (Martins, 2008, p. 103). O PPP da escola do campo é o documento que norteia as práticas de gestão e as ações pedagógicas, cuja construção simboliza a identidade da escola camponesa.

Como metodologia de organização escolar, a Pedagogia da Alternância articula momentos de ensino entre atividades escolares e atividades socioprofissionais. Para compreender seus objetivos, as disciplinas escolares abrangem temáticas voltadas às necessidades da sociedade, relacionando a vida coletiva, o meio ambiente, a formação profissional, social, política e econômica com disciplinas básicas (Teixeira, Bernartt \& Trindade, 2008). As instituições de ensino que se organizam segundo o regime da Alternância buscam introduzir em seu currículo outros saberes que estejam de acordo com o contexto em que se insere a escola, os educandos e a comunidade.

Gimonet (2007, p. 28) destaca como finalidades básicas da Alternância "a formação integral da pessoa, a educação e, de maneira concomitante, a orientação e a 
inserção socioprofissional", fundamentalmente comprometidas com o desenvolvimento da comunidade onde está inserido o CEFFA. Desse modo, as práticas pedagógicas se comprometem com os educandos, oferecendo-lhes subsídios para que articulem teoria, técnica e prática, com vistas à sua formação global, preparando-os para o acesso a programas, empregos ou para prosseguir nos estudos.

Os princípios norteadores da alternância pedagógica se comprometem com a primazia da experiência. Segundo Gimonet (2007), os saberes devem percorrer a vida e a escola, articulando-se entre espaços de formação que ocorrem em um processo de três tempos: 1) o meio familiar e profissional, que permite a socialização e a observação; 2) o CEFFA que possibilita a formalização e estruturação dos saberes teóricos e formais; e, 3) o meio em que serão aplicados os saberes a partir de experimentações. $\mathrm{O}$ autor destaca, conforme demonstra-se na Figura 1, que esses três tempos estão imbricados e sua sequência caracteriza a unidade de formação da Pedagogia da Alternância. Desde a chegada ao CEFFA, o educando transita entre os três tempos, socializando e investigando no meio vivencial, formalizando os saberes no CEFFA e aplicando-os posteriormente, sendo que esse processo é contínuo e tem como propósito viabilizar ao educando a ligação e interação entre os dois espaços, o meio vivencial e o CEFFA.

Figura 1: Sequência de alternância ou unidade de formação.

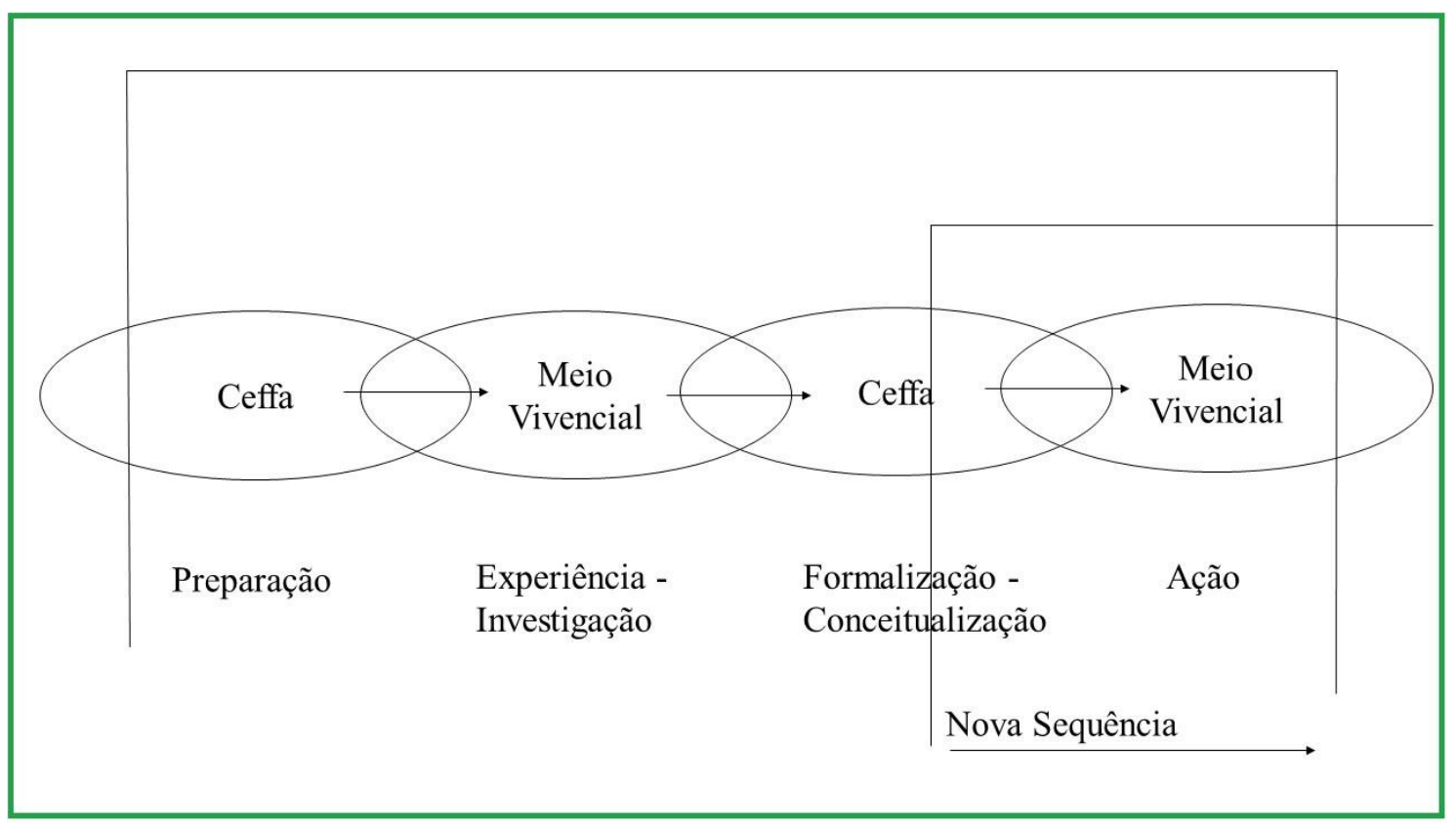

Fonte: Adaptado de Gimonet (2007, p. 30).

\begin{tabular}{|l|l|l|l|l|l|l|l|}
\hline Rev. Bras. Educ. Camp. & Tocantinópolis & v. 3 & n. 1 & p. 287-312 & jan./abr. & 2018 & ISSN: 2525-4863 \\
\hline
\end{tabular}


Conforme demonstra Gimonet (2007), o primeiro contato do educando com o CEFFA ocorre em um momento de preparação, no qual ele passa dias vivenciando as rotinas e adaptando-se a esse novo meio. A fase preparatória visa apresentar aos sujeitos os princípios, os objetivos e os fundamentos pedagógicos da alternância para que, assim, optem conscientemente sobre sua permanência ou não nesse processo formativo. Além do mais, a fase preparatória possibilita uma aproximação inicial com o CEFFA, dando início à sequência de alternância entre momentos no meio vivencial e momentos no Centro de Formação, intercalando-se as vivências com as comunidades e com as famílias. Essas servem, primeiramente, para investigar e observar os saberes experienciais que, após as vivências diretas nos centros de formação, permitem a estruturação e a formalização dos saberes teóricos, serve também para a concretização prática desses saberes.

Seguindo essa concepção, a articulação da teoria com a prática se efetiva em espaços que alternam entre a escola e a propriedade, comunidade, assentamento, acampamento ou movimento social a que o educando se vincula. As atividades devem primar por uma formação contínua de inter-relação entre os três tempos - família, instituição e comunidade -, obedecendo a um princípio formativo integral do sujeito. Isso, tendo em vista a exigência profissional, humana e social. Todos os envolvidos - educandos, educadores, famílias e comunidade -, tornam-se co-formadores, de modo que, mediante os princípios de cooperação e ação, os saberes são partilhados e o educando tem autonomia na construção de sua formação (Gimonet, 2007).

Para Gimonet (1998), a perspectiva da formação por Alternância eleva o educando ao centro do debate, sendo considerado como um adulto alternante, ator de sua própria formação. Conforme demonstra-se na Figura 2, o autor destaca seis componentes que estão em constante interação com o jovem alternante que busca envolver-se com o lugar de sua experiência, com os sistemas de gestão e operação pedagógicos, com as ações de formação do projeto educativo, com todos os parceiros dos tempos de formação e com a rede de formadores do conjunto. 
Figura 2: Esquema dos componentes em interação na formação por Alternância.

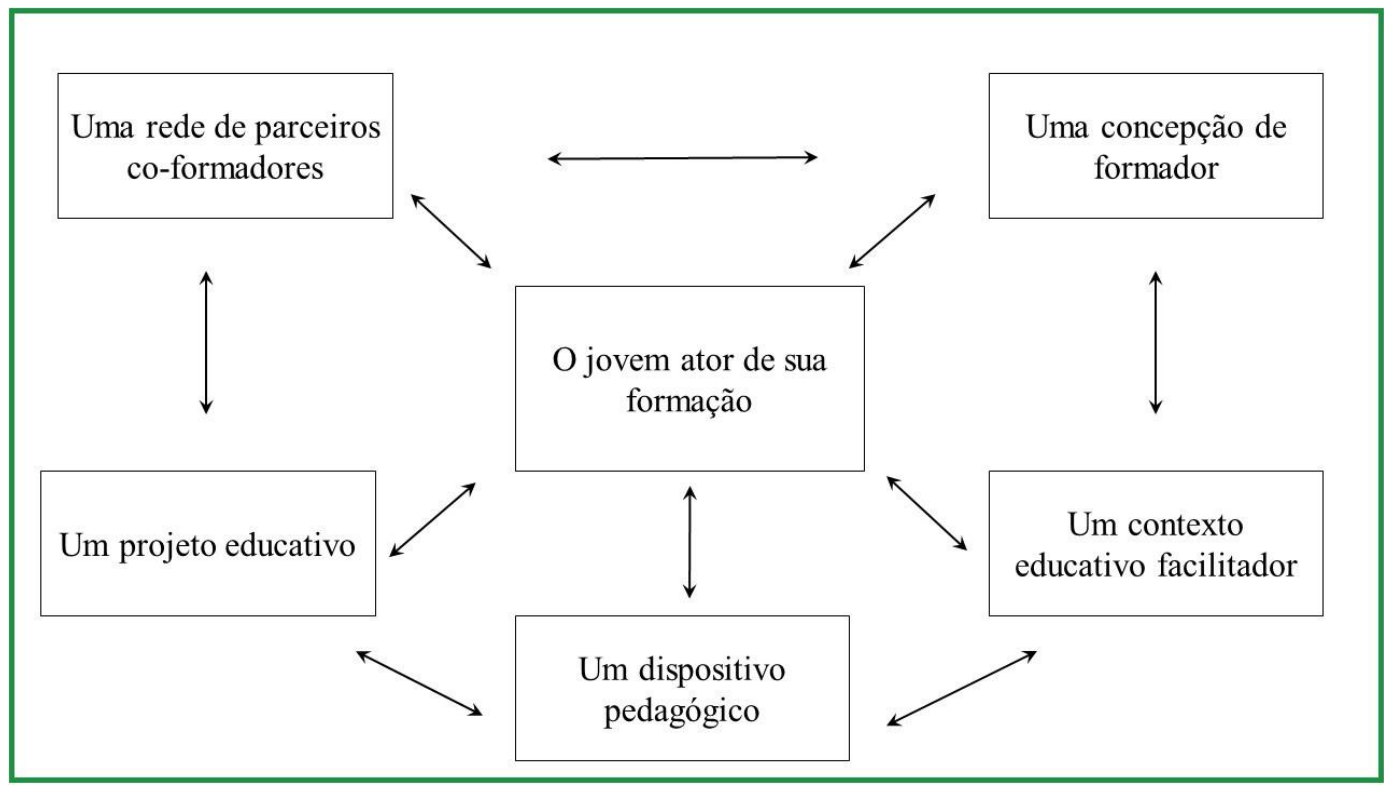

Fonte: Adaptado de Gimonet (1998, p. 2).

Os métodos e os instrumentos pedagógicos são sistematizados segundo as condições objetivas encontradas em cada momento enfrentado pelas instituições e conforme cada turma de educandos. Com vistas ao permanente movimento da formação humana, a metodologia está em constante construção e faz parte da prática dos educandos e educadores envolvidos no processo da Alternância. Tais proposições evidenciam que a Pedagogia da Alternância não consiste apenas em um método pedagógico que alterna Tempo Escola (TE) e Tempo Comunidade (TC). Essa é uma condição necessária para a efetivação desse método, mas não a única. Sua metodologia de organização enfatiza o processo de aprendizagem centrado no educando em ação e em interação com sua família, sua comunidade e a instituição formadora.

Os estudos apresentados por Gimonet (1998; 2007) destacam a Pedagogia da Alternância como um construto pedagógico completo, identificando suas finalidades, objetivos e instrumentos. Essa arquitetura pedagógica é encontrada nos CEFFA, que seguem as definições e propostas do método. No entanto, atualmente, os princípios da Alternância como prática educativa podem ser encontrados não apenas no sentido de uma pedagogia em si, mas também como um modelo organizativo em interlocução com outras metodologias.

Sobreira e Silva (2014) destacam que além das experiências encontradas nas Escolas Famílias Agrícolas (EFA) e nas Casas Familiares Rurais (CFR), existe no 
Brasil uma expansão de práticas alternantes, que pode ser percebida em programas governamentais como o Programa ProJovem Campo - Saberes da Terra, desenvolvido no âmbito do Ministério da Educação e o Programa Residência Agrária, desenvolvido no âmbito do Ministério do Desenvolvimento Agrário, e, também, em Cursos ligados à Via Campesina oferecidos pela Fundação de Desenvolvimento da Pesquisa (Fundep) ou pelo Instituto Técnico de Capacitação e Pesquisa da Reforma Agrária (Iterra). Estas práticas conjugam tempo escola e tempo comunidade e se consolidam na interação entre teoria e prática, experiência e reflexão.

Assim, por ser uma metodologia que permite $o$ acesso e a permanência da população do e no campo, a Pedagogia da Alternância atualmente no Brasil é assumida pela Educação do Campo e está inserida em diversos programas e projetos educacionais, sendo adotada por políticas setoriais, como as defendidas pelo Ministério do Desenvolvimento Agrário (MDA), mediante o Programa Nacional de Educação na Reforma Agrária (Pronera). Além disso, de acordo com Hage et al. (2011), o Movimento dos Trabalhadores Rurais Sem Terra (MST) tem fundamentado suas propostas educacionais utilizando princípios da Pedagogia da Alternância, como é o caso das escolas localizadas em assentamentos da reforma agrária, que seguem os princípios educativos pautados pelo MST.

Após o reconhecimento de algumas especificidades da Pedagogia da Alternância, verificando sua construção histórica e social, prosseguimos o estudo com vistas a compreender a Alternância como uma organização metodológica educativa. Levando em consideração que nosso campo investigativo é uma escola localizada em um assentamento da reforma agrária, o Instituto Educar, se faz necessário identificar como a prática alternante se efetiva nesse espaço. Salientamos, todavia, que as práticas alternantes, mesmo não se solidificando como uma pedagogia, buscam manter o objetivo norteador da mesma, proporcionando, assim, aos povos do campo, uma educação que condiz com suas necessidades, possibilitando ao sujeito estudante um contato direto com o seu meio.

\section{O Instituto Educar: uma conquista dos trabalhadores rurais}

O processo de constituição do Instituto Educar se efetivou diante de um contexto histórico de ocupações, embates, lutas e conquistas resultantes dos conflitos por terra enfrentados por trabalhadores rurais. O Instituto Educar está localizado em um assentamento no norte do estado do 
Rio Grande do Sul, fazendo parte de uma rota de luta pela terra que se situa próxima aos municípios de Pontão, Ronda Alta e Sarandi.

Segundo Benincá (2016), foi nessa região altamente agrícola que em 1981 surgiu o acampamento dos "Sem-Terra", com mais de 600 famílias alojadas ao longo da estrada, provindas de diversos municípios da região, descendentes de imigrantes europeus e de caboclos. A região ficou reconhecida pela expressão das lutas de classe, quando os povos atingidos pela ação dos acampamentos, “conseguiram operar a transformação de sua concepção de mundo, depositaram sua fé noutra filosofia de ação: a filosofia de transformação da atual estrutura social" (Benincá, 2016, p. 200).

Após anos, uma das consequências da luta consciente dos pequenos agricultores nessa região foi à criação do Instituto Educar. Fundado no mês de janeiro de 2005, esse educandário se estabeleceu mediante uma parceria com o Instituto Federal de Educação, Ciência e Tecnologia do Rio Grande do Sul (IFRSCampus Sertão) e o Pronera, e vem atuando há mais de dez anos na formação de jovens e adultos que pertencem a acampamentos, assentamentos, reassentamentos e movimentos sociais de diversas partes do país.
Segundo consta no PPP (Instituto Educar, 2012), o Instituto Educar se compromete com a formação profissional do homem do campo, com a preservação do meio ambiente e com o desenvolvimento sustentável dos assentamentos, pautando-se nos seguintes objetivos:

a) Promover a ação de capacitação de agricultores assentados e acampados nas áreas de Reforma Agrária e de pequenos agricultores, nas mais diversas áreas do conhecimento técnico-científico.

b) Propiciar o acesso à escolarização em todos os níveis, elevando o grau de escolarização dos povos do campo.

c) Estimular desenvolvimento rural e a melhoria de vida do homem e da mulher do campo, da infância a velhice e de suas comunidades.

d) Atuar na defesa, prevenção e conservação do meio ambiente, incentivar a agroecologia e promover a visão sistêmica da produção e o desenvolvimento sustentável.

e) Apoiar iniciativas relacionadas com a promoção da reforma Agrária, de um projeto popular de desenvolvimento do campo de um modelo de agricultura que garanta a soberania alimentar e a vida do povo no e do campo.

f) Formar agricultores, com especialização técnica em agroecologia, que contribuam para a organização de base dos trabalhadores e a ampliação de um novo modelo de agricultura de desenvolvimento para o campo brasileiro, em vista da manutenção do homem e mulher do campo e sua qualidade de vida (Instituto Educar, 2012, p. 8). 
O Instituto Educar oferece atualmente dois cursos, sendo um de nível médio, o Curso Técnico em Agropecuária com Ênfase em Agroecologia Integrado ao Ensino Médio, em parceria com o IFRS, campus Sertão e com o Pronera, e outro, em nível pós-médio, o Curso Superior em Agronomia com Ênfase em Agroecologia, em parceria com a Universidade Federal da Fronteira Sul e o Pronera.

$\mathrm{O}$ Instituto Educar segue metodologias específicas que podem ser articuladas de acordo com as demandas locais, procurando sintonizar as práticas pedagógicas com os movimentos sociais representados pelos educandos e suas famílias. Por isso, descrever sua metodologia pautando-se apenas em uma forma peculiar de pedagogia se torna inviável, devido às diversas articulações existentes para mobilizar uma formação participativa, de acordo com as especificidades de cada sujeito que passa por esse ambiente.

Tendo em vista que o método pedagógico do Instituto não é dogmatizado, pois continua em permanente mudança seguindo as transições de pessoal, políticas e sociais, estabelecemos um vínculo com a equipe pedagógica e de coordenação que nos apoiou para a descrição da metodologia que se constitui, neste momento, como guia das práticas pedagógicas estabelecidas.
Segundo os colaboradores com quem travamos esse diálogo inicial, o Instituto Educar foi uma conquista dos trabalhadores rurais que buscavam uma educação digna a seus povos. Como um feito recente, que completou apenas doze anos em 2017, as diretrizes organizativas do Instituto Educar se apoiaram em experiências de outras escolas já estabelecidas há mais tempo, que demonstravam frutos significativos nos assentamentos. Segundo a manifestação de um colaborador, todos os sujeitos envolvidos com o Instituto Educar são multiplicadores capazes de contribuir com o processo de formação dos membros do coletivo. Ainda, destaca que as ações realizadas nesse contexto são avaliadas em reuniões semanais, sendo que quinzenalmente ocorre o que denominam leitura do processo, que são encontros de coordenadores pedagógicos e de turma, organizados para refletir sobre os processos metodológicos realizados no Instituto Educar.

A inserção exploratória no campo investigado nos proporcionou uma percepção sobre as singularidades educativas propostas pelo Instituto Educar. Constatamos, de fato, que as metodologias adotadas na instituição não são cópias de manuais e, tampouco estão fielmente descritas em livros e periódicos. O Instituto Educar se organiza em instâncias 
representativas, como uma forma estratégica de manter a dinâmica e o funcionamento da Escola. Educandos, educadores, funcionários e todos que convivem nesse ambiente são inseridos em algum núcleo, respondem e se articulam nessa coletividade. A coletividade primária é denominada de Núcleo de Base (NB), que assume a função de "ser a instância de base do processo de gestão (da escola e do MST), fazer a formação políticoideológica, implementar as tarefas determinadas pelas coletividades maiores" (Iterra, 2004, p. 46). A divisão dos núcleos busca integrar todos os educandos, para isso são cumpridos alguns critérios como: cada NB deve contar com a participação de uma representatividade feminina; os educandos oriundos da mesma localidade são distribuídos em diferentes núcleos; os educandos de um mesmo movimento são divididos para que cada núcleo conte com uma representatividade quando possível.

O Instituto Educar defende uma metodologia pensada pela coletividade, por acreditar em uma educação para todos e todas, uma educação das pessoas inseridas em um conjunto maior. Os processos educativos do Instituto Educar são realizados pelos sujeitos que fazem parte desse coletivo. Nesse contexto, a organização ocorre mediante um regime de alternância, no qual cada turma percorre um ritmo intercalando períodos entre TE, de permanência e maior influência da escola e TC, de permanência e maior influência da comunidade.

O TE ocorre no Instituto Educar e constitui-se de momentos em que os alunos têm aulas práticas e teóricas, oficinas, atividades de campo, capacitações técnicas, dentre outras ocupações. A recorrência dos dias é determinada conforme cada turma, normalmente, são 90 dias consecutivos em que os alunos vivenciam diariamente processos coletivos de ensino. Nesse período os alunos ficam alojados na escola, divididos em quartos femininos e masculinos e assumem total responsabilidade pela organização do ambiente. As atividades são mantidas diante de uma disciplina organizativa em que cada educando fica responsável, junto com o seu coletivo, por manter a ordem de determinado setor.

Durante o TE, os horários são definidos semanalmente, podendo ocorrer aula nos três turnos e também nos finais de semana. Não há uma carga diária préestabelecida, os dias se efetivam no decorrer de tempos educativos, que são momentos onde os alunos se dedicam a determinadas tarefas. Os tempos educativos visam à organização e à autoorganização dos educandos, como forma de alcançar os objetivos almejados. Podemos descrever os seguintes tempos para esse período: tempo aula, tempo 
trabalho, tempo formatura (para turmas finalistas), tempo oficina, tempo leitura, tempo estudo, tempo cultura, tempo notícias, tempo reflexão escrita, tempo educação física, tempo núcleo de base (NB), tempo verificação de leitura (VL) (Iterra, 2004).

Normalmente, o dia inicia com o café da manhã às 6h30min, sendo que até às 7h30min deve ocorrer a limpeza do refeitório, a organização dos quartos e a higiene pessoal. Às $7 \mathrm{~h} 40 \mathrm{~min}$ começa a motivação, momento no qual todos os alunos se encontram para iniciar o dia cantando o hino do MST, com palavras de ordem e com a mística, em que alguns alunos (cada dia um grupo diferente) ficam responsáveis por realizar uma reflexão, podendo ser sobre questões políticas, sociais ou culturais atuais, em memória a grandes personagens, ou de alerta a situações de indisciplina. Também nesse momento são referidos em voz alta os acontecimentos do dia anterior $\mathrm{e}$ as principais notícias. As aulas iniciam às $8 \mathrm{~h}$ e se estendem até às $12 \mathrm{~h}$, retornando das $14 \mathrm{~h}$ às $17 \mathrm{~h}$, com intervalos para almoço e lanches. Podem ser intercalados com o tempo aula, tempos educativos de leitura, oficina e estudo.

Como uma continuidade do TE ocorre o TC, período em que os alunos retornam aos seus assentamentos ou aos seus movimentos para não se distanciar dos vínculos com a comunidade. Da mesma forma que o TE, o TC ocorre em um período consecutivo, normalmente de 90 dias, em que o educando vai experimentar, socializar, pesquisar e exercitar a liderança. Em cada TC o Instituto Educar orienta atividades específicas a serem realizadas, que visam dar continuidade ao processo formativo de cada educando. Os tempos educativos no TC dividem-se em: tempo trabalho, tempo leitura e estudo, tempo formatura, tempo $\mathrm{NB}$, tempo reflexão escrita, tempo notícias e tempo cultura. Nesse momento as maiores influências são dos familiares e dos movimentos sociais.

O Instituto Educar estabelece, para cada etapa, algumas "situações de aprendizagem" a serem desenvolvidas no decorrer do curso, são outras possibilidades, além dos tempos educativos, que devem ser organizadas, planejadas e preparadas em conjunto. São consideradas situações de aprendizagem: seminário de crítica e autocrítica, trabalho voluntário, contribuição ao Instituto, participação em eventos, viagens de estudo ou visitas educativas, semana dos clássicos, seminários, mostra cultural. As situações de aprendizagem contemplam os objetivos e as demandas de cada turma, e se efetivam ao cumprir uma intencionalidade pedagógica que leve em conta o processo educativo em andamento. 
Diante do exposto, podemos perceber que o princípio educativo do Instituto Educar compreende o educando como um sujeito que protagoniza o seu processo formativo. A alternância, os tempos educativos e as situações de aprendizagem, atuam como pilares metodológicos que contribuem para que o educando exerça esse protagonismo em seus processos de aprendizagem.

\section{Considerações Finais}

Com base na investigação teórica realizada, identificamos que a Educação do Campo se efetiva mediante lutas sociais que buscam os direitos da população do campo e se consolida como uma educação que prioriza a diversidade humana em suas dimensões histórica, política e social ao conceber o sujeito como protagonista principal de sua formação. A Pedagogia da Alternância, por sua vez, se estrutura a partir das necessidades dos agricultores como uma prática educativa que busca atender às peculiaridades e demandas do povo rural. Atualmente, a Pedagogia da Alternância é uma modalidade à Educação do Campo e pode ser utilizada como uma pedagogia em si ou como uma forma de organização metodológica.

Em nossa inserção exploratória constatamos que no Instituto Educar há uma organização metodológica alternante, que segue o regime da alternância entre Tempo Escola e Tempo Comunidade e que prioriza a educação das pessoas inseridas em uma coletividade. Os processos educativos do Instituto Educar são realizados pelos sujeitos que ali vivenciam e seguem o princípio que compreende o educando como um sujeito que protagoniza o seu processo formativo.

O Instituto Educar - assim como a Educação do Campo - se constituiu historicamente mediante lutas sociais que priorizavam os direitos da população do campo e, por esse motivo, pauta uma formação voltada às dimensões histórica, política e social, na qual o sujeito é visto como o protagonista de sua formação. Nesse sentido, a Alternância é utilizada como uma forma de organização metodológica visando à experiência vivida que articula teoria e prática, escola e comunidade, possibilitando que os jovens mantenham o vínculo com o campo e, fundamentalmente, apliquem seus conhecimentos teóricos em suas propriedades.

Reconhecemos que esse cenário de Educação do Campo, com enfoque para a organização metodológica alternante, tal como é desenvolvida no Instituto Educar, garante aos povos do campo os seus direitos de vivenciar processos educativos a partir das particularidades de sua cultura. Mesmo que a prática alternante vivenciada 
nesse espaço não se constitua como uma pedagogia em si, mantém o objetivo norteador da mesma proporcionando, assim, aos povos do campo, uma educação que condiz com suas necessidades, possibilitando ao estudante um contato direto com o seu meio.

\section{Referências}

Begnami, J. B. (2003). Formação pedagógica de monitores das Escolas Famílias Agrícolas e alternâncias: um estudo dos processos formativos de cinco professores (Dissertação de Mestrado). Universidade Nova de Lisboa e Université François Rabelais de Tours-França, Minas Gerais.

Benincá, E. (2016). Conflito Religioso e Práxis: o conflito religioso na ação política dos acampamentos de Encruzilhada Natalino e da Fazenda Annoni. Passo Fundo, RS: Editora IFIBE.

Brasil. (1996). Lei de Diretrizes e Bases da Educação Nacional n ${ }^{\circ}$ 9.394/96, de 20 de dezembro de 1996. Brasília, DF: MEC/Conselho Nacional de Educação.

Brasil. (2001). Ministério da Educação. Conselho Nacional de Educação. Parecer $n^{o}$. 36, de 4 de dezembro de 2001. Dispõe sobre Diretrizes Operacionais para a Educação Básica nas Escolas do Campo. Recuperado de: http://pronacampo.mec.gov.br/images/pdf/ $\underline{\text { mn_parecer_36_de_04_de_dezembro_de }}$ 2001.pdf

Brasil. (2004). Grupo de Trabalho de Educação do Campo. Referências para uma política nacional de educação do campo: caderno de subsídios. Brasília, DF.
Brasil. (2007). Secretaria da Educação Continuada, Alfabetização e Diversidade. Cadernos SENAD/MEC. Educação do campo: diferenças mudando paradigmas. Brasília, DF. Recuperado de: http://portal.mec.gov.br/secad/arquivos/pdf leducacaocampo.pdf

Brasil. (2010). Decreto n. 7.352/10, de 04 de novembro de 2010. Dispõe sobre a política de educação do campo e o Programa Nacional de Educação na Reforma Agrária-Pronera. Brasília, DF. Recuperado de: http://portal.mec.gov.br/docman/marco2012-pdf/10199-8-decreto-7352-de4-denovembro-de-2010/file

Caldart, R. S. (2002). Por uma educação do campo: traços de uma identidade em construção. In Kolling, J. E., Cerioli, P. R., \& Caldart, R. S. (Orgs.). Educação do campo: identidade e políticas públicas (pp. 18-25). Brasília, DF.

Caldart, R. S. (2013). Educação do campo. In Caldart, R. S. et al. (Org.). Dicionário da educação do campo (pp. 257-265). Rio de Janeiro, RJ/São Paulo, SP: Escola Politécnica de Saúde Joaquim Venâncio, Expressão Popular.

Estevam, D. O. (2001). Casa familiar rural: a formação com base na pedagogia da alternância em Santa Catarina (Dissertação de Mestrado). Universidade Federal de Santa Catarina, Santa Catarina.

FONEC. (2010). Fórum Nacional de Educação do Campo. Carta de criação do Fórum Nacional de Educação do Campo. Brasília, DF.

Gimonet, J. C. (1998). A alternância na formação: método pedagógico ou novo sistema educativo? A experiência das Casas Familiares Rurais. In Demol, J., \& Pilon, J. (Orgs.). Alternance, developpement personnel et local (pp. 5166) Paris: L'Harmattan. 
Gimonet, J. C. (2007). Praticar $e$ compreender a pedagogia da alternância dos CEFFAs. Petrópolis, RJ: Vozes.

Hage, S. M., Cordeiro, G. N. K., \& Reis, N. S. (2011). Pedagogia da Alternância e seus desafios para assegurar a formação humana dos sujeitos e a sustentabilidade do campo. Em Aberto, 24(85), 115-125. Recuperado de: http://emaberto.inep.gov.br/index.php/ema berto/article/view/2489

INCRA. (2016). Homepage. Recuperado de:

http://www.incra.gov.br/educacao_pronera

Instituto Educar. (2012). Projeto pedagógico do curso técnico em agropecuária integrado ao ensino médioPolo Pontão. IFRS: Sertão.

ITERRA. (2004). Instituto de Educação Josué de Castro. Método pedagógico. Veranópolis, RS.

Kolling, E. J., Vargas, M. C., \& Caldart, R. S. (2013). MST e Educação. In Caldart, R. S. et al. (Orgs.). Dicionário da educação do campo (pp. 500-507). Rio de Janeiro, RJ/São Paulo, SP: Escola Politécnica de Saúde Joaquim Venâncio, Expressão Popular.

Martins, F. J. (2008). Organização do trabalho pedagógico e Educação do Campo. Revista Educação, 33(1), 93-106. Recuperado de: https://periodicos.ufsm.br/reveducacao/ article/view/21/pdf

Menezes Neto, A. J. (2009). Formação de professores para a educação do campo: projetos sociais em disputa. In Martins, A., \& Rocha, M. (Orgs.). Educação do campo: desafios para a formação de professores (pp. 25-38). Belo Horizonte, MG: Autêntica.
Santos, C. A., Molina, M. C., \& Jesus, S. (Orgs.). (2010). Memória e história do Pronera: contribuições para a educação do campo no Brasil. Brasília, DF: Ministério do Desenvolvimento Agrário.

Sobreira, M., \& Silva, L. (2014). Vida e construção do conhecimento na pedagogia da alternância. Revista Eletrônica de Educação, 8(2), 212-227. DOI: http://dx.doi.org/10.14244/19827199915

Teixeira, E., Bernartt, M., \& Trindade, G. (2008). Estudos sobre a pedagogia da alternância no Brasil: revisão de literatura e perspectivas para a pesquisa. Educação $e$ Pesquisa, 34(2), 227-242. Recuperado de: http://www.scielo.br/pdf/ep/v34n2/02.pdf

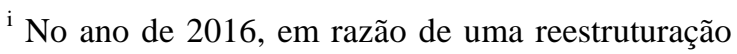
ministerial, a Secadi foi extinta, causando desconforto à comunidade que defende a representatividade da mesma na educação de direitos humanos, no âmbito da cidadania, inclusão e combate às desigualdades.

ii Esses dados estão disponíveis publicamente no site do Incra, no item Pronera - Educação. Disponível em: <http://www.incra.gov.br/educacao_pronera>. Acesso em 12 mai. 2016.
}

Recebido em: 02/02/2018 Aprovado em: 23/02/2018 Publicado em: 24/04/2018 
Como citar este artigo / How to cite this article / Como citar este artículo:

APA:

Bonavigo, L., \& Caimi, F. E. (2018). A Pedagogia da Alternância no contexto da Educação do Campo: a experiência do Instituto Educar. Rev. Bras. Educ. Camp., 3(1), 287-312.

ABNT:

BONAVIGO, L.; CAIMI, F. E. A Pedagogia da Alternância no contexto da Educação do Campo: a experiência do Instituto Educar. Rev. Bras. Educ. Camp., Tocantinópolis, v. 3, n. 1, p. 287-312, 2018.

\title{
ORCID
}

\author{
Luana Bonavigo \\ (iD) http://orcid.org/0000-0002-3323-1708
}

Flávia Eloisa Caimi

(iD) http://orcid.org/0000-0001-5509-6060

Declaramos que as autoras Luana Bonavigo e Flávia Eloisa Caimi foram responsáveis pela elaboração, análise e interpretação dos dados, pela escrita e revisão do conteúdo do manuscrito. As autoras também foram responsáveis pela aprovação da versão final a ser publicada. 